\title{
Veteran Family Reintegration, Primary Care Needs, and the Benefit of the Patient-Centered Medical Home Model
}

\author{
Ramon Hinojosa, PhD, Melanie Sberna Hinojosa, PhD, Karen Nelson, MD, \\ and David Nelson, MS, PhD
}

\begin{abstract}
Men and women returning from the wars in Afghanistan and Iraq face a multitude of difficulties while integrating back into civilian life, but the importance of their veteran status is often overlooked in primary care settings. Family physicians have the potential to be the first line of defense to ensure the well-being of veterans and their families because many will turn to nonmilitary and non-Veterans Affairs providers for health care needs. An awareness of the unique challenges faced by this population is critical to providing care. A patient-centered medical home orientation can help the family physician provide veterans and their families the care they need. Specific recommendations for family physicians include screening their patient population; providing timely care; treating the whole family; and integrating care from multiple disciplines and specialties, providing veterans and families with "one-stop shopping" care. An awareness of the unique challenges faced by veterans and their families translates into better overall outcomes for this population. ( $\mathrm{J} \mathrm{Am}$ Board Fam Med 2010;23:770-774.)
\end{abstract}

Keywords: Veterans, Medical Home, Patient-Centered Care, Primary Health Care

Men and women returning from the wars in Afghanistan and Iraq face a multitude of difficulties

This article was externally peer reviewed.

Submitted 20 April 2010; revised 6 July 2010; accepted 26 July 2010.

From the Rehabilitation Outcomes Research Center, North Florida/South Georgia Veterans Health System, Gainesville, FL (RH); the Department of Epidemiology and Health Policy Research, Institute for Child Health Policy, University of Florida, Gainesville (MSH); the Department of Family and Community Medicine, Waukesha Family Medicine Residency Program (KN) and the Department of Family and Community Medicine, Center for Healthy Communities (DN), Medical College of Wisconsin, Milwaukee.

Funding: This work was supported by the Department of Veterans Affairs Rehabilitation Outcomes Research Center and the North Florida/South Georgia Veteran Affairs Medical Center.

Conflict of interest: none declared.

Corresponding author: Ramon Hinojosa, $\mathrm{PhD}$, North Florida/ South Georgia Veterans Health System, Rehabilitation Outcomes Research Center, Commerce Building, 300 East University Avenue, Suite 350, Gainesville, FL 32601 (E-mail: ramon.hinojosa@va.gov).

\footnotetext{
See Related Commentary on Page 700.
}

while integrating back into civilian life. This group is often overlooked in primary care settings because there is a popular belief that many veterans returning from overseas deployments receive health care through the Military Health System or Veterans Administration (VA) clinics and hospitals. The recent emphasis on the patient-centered medical home $(\mathrm{PCMH})$ as a setting for primary care physicians to provide comprehensive care to families ${ }^{1}$ makes it more important to highlight the difficulties that can arise when veterans reintegrate into families after deployment, especially given that many will turn to nonmilitary and non-VA providers for health care needs. Unfortunately, there is little in the current literature to guide primary care physicians when they are assisting their veteran patients. The purpose of this article is to raise awareness of the issues veterans and their families face during the veteran's reintegration and to provide primary care physicians with ideas of how to identify and begin treating veterans in their patient populations.

To be sure, many veterans routinely use the VA health system to receive care, but only half of those 
deployed since 2002 are eligible for VA care. ${ }^{2}$ For some, VA health benefits are limited to 60 months after discharge, after which long-term physical and mental health care needs to pass to nonmilitary and non-VA physicians or go untreated. For others, good private insurance, long-established relationships with family physicians, or the stigma associated with VA health care means they will seek care outside of the and VA system. ${ }^{3}$ One estimate suggests that only one third of all eligible veterans take advantage of the Veterans Health Administration's health care facilities and mental health services. ${ }^{4}$ From the current wars in Afghanistan and Iraq, despite aggressive outreach by VA, roughly $40 \%$ of eligible Operation Enduring Freedom (OEF)/ Operation Iraqi Freedom (OIF) veterans use VA health services. ${ }^{2}$ In addition, many veterans who have mental health care needs do not seek or receive VA care despite the help available. With mental health, veterans are more likely to use non-VA primary care clinics ${ }^{5,6}$ because of the stigma associated with mental health service use through military support mechanisms. ${ }^{3,7}$ In short, nonmilitary and non-VA primary care physicians are likely to have veterans in their patient populations. Although the VA does treat a limited number of veterans' family members, most family members are treated in non-VA settings.

The magnitude of non-VA primary care physicians' future involvement in veteran care is highlighted by the number of people in the United States affected by the recent wars in Afghanistan and Iraq. As of December 2009 there were 179,090 active duty and 71,217 reserve component service members on duty as part of OEF and/or OIF. ${ }^{8}$ Of those currently deployed, $54 \%$ are married $(113,108)$; $85 \%$ of these married personnel report children at home $(95,913)$. In all, there are some 2052,405 service members who have been at some point deployed to the wars in Iraq and Afghanistan. ${ }^{9}$ Combined with their family members, an estimated $2 \%$ to $3 \%$ of the total American population has been touched directly the wars in Afghanistan and Iraq. This number will continue to grow as the wars continue, and does not account for all family members (ie, those who do not reside with the veteran) or friends and acquaintances who have regular contact with veterans.

A host of social and psychological difficulties plague deployed veterans. Such difficulties include posttraumatic stress and depressive symptoms, ${ }^{10-13}$ which are related to elevated levels of use and abuse of substances ${ }^{14}$ like alcohol ${ }^{15}$ and tobacco ${ }^{16}$ and elevated rates of suicide. ${ }^{17,18}$ Studies report rates of posttraumatic stress disorder (PTSD) among returning soldiers ranging from $4 \%{ }^{19}$ to $31 \%{ }^{10}$ and rates of depression ranging from $3 \%^{20}$ to $25 \% .^{21}$ PTSD and depression are associated with greater family and marital instability, higher rates of relationship distress, ${ }^{22}$ and more negative interpersonal relationships with partners ${ }^{23}$ and children. ${ }^{24}$

Primary care physicians should be aware that reintegration after deployment is a particularly stressful time for veterans and their families. ${ }^{25}$ Problems associated with reintegration can last for years. ${ }^{26}$ Family strife and relationship dissolution can result, ${ }^{27}$ leaving the veteran socially isolated, which can exacerbate mental health difficulties, retard physical recovery, and interfere with rehabilitative efforts. Family conflict is also a known factor of veteran homelessness. ${ }^{28-30}$ Thus, access, healthseeking behaviors, and mental health and relationship issues add up to deployed veterans having earlier and greater comorbidities ${ }^{31,32}$ and an increased likelihood of early mortality. ${ }^{33}$

There is a strong need to increase awareness of veterans' issues in primary care settings, with increased attention paid to social factors, such as family reintegration after deployment, that can exacerbate physical and mental health difficulties for both veterans and their family members. ${ }^{34-37}$ The American Academy of Family Physicians and other primary care physician organizations developed the PCMH as a comprehensive model of care for children, youth, and adults. The principles of the PCMH include, among other things, a personal physician who provides a whole-person orientation, a focus on family-centered care that is appropriate and timely, and coordinated and integrated care that contributes to the overall health and care of the patient. ${ }^{38}$ For veterans who are seeking medical care in a nonmilitary or non-VA setting, the family physician has the potential to be the first line of defense to ensure the well-being of veterans and their families. ${ }^{5,6,39}$ Family physicians, for their part, can do a number of things to ensure veterans receive the care they deserve. First, to provide wholeperson orientation, family physicians should screen their patients to identify any veterans or veterans' family members in their patient population. This can be done with a few simple questions on intake forms, such as, Are you a veteran or do you live 
with someone who is a veteran? A follow-up question would inquire about their deployment status: Was the person who is a veteran ever deployed as part of a humanitarian, peace-keeping, combat, or combat support force? If yes, when and where was the veteran deployed and in what capacity (example: Iraq, convoy security)? These screening questions can provide family physicians with critical and necessary information for treating patients. Many patient intake forms already include information about substance use behaviors, such as daily consumption of tobacco and alcohol, so adding a question about veteran status can be a simple and efficient way to provide a higher level of care. When veterans are identified, physicians can more closely monitor substance use by asking about usage levels during each clinic visit. Identified veterans can also be provided with psychometrically validated shortform screens such as the 7-item Combat Exposure Scale, ${ }^{40}$ which assesses levels of exposure to specific military stressors, or the 17-item PTSD Checklist-Military Version from the National Center for PTSD. For depression, the short, 10-item version of the Center for Epidemiologic Studies Depression (CESD) scale has good predictive accuracy; is reported as reliable, valid, and sensitive to change over time ${ }^{41}$; and has been used in general, patient, and older adult populations, including veterans. ${ }^{42}$ Family physicians can ensure family-centered care by providing screening tools like the CESD-10 to both veterans and their family members. None of these screening tools present a significant time burden for veterans or for physicians, and they can be easily administered in the clinical setting. These instruments will provide physicians with a quick assessment of whether or not to recommend referral for mental health services. This is an efficient means to quickly address the unique needs of veterans and their families while at the same time initiating the process of coordinated care should veterans need additional services. The potential benefit to families is that veterans' mental health difficulties can be identified and treated before they disrupt relationships. Providing care to the whole family can be done by identifying veterans and monitoring the veteran's and the family's mental health and substance use. The strain of reintegration after deployment can last for years. ${ }^{25,26}$ Monitoring the whole family can ameliorate family strain and help families to avoid problems down the road, which in turn is linked to better health outcomes for all ${ }^{31-33}$ because veterans' physical and mental health problems are as likely as not to affect family members' health and well-being.

Family physicians should make sure that veterans have access to care in a timely manner. There is a tendency for veterans to use family physicians as "de facto" mental health professionals. ${ }^{39}$ Identifying veterans through simple questions on patient intake forms and screening them with the short-form Combat Exposure Scale, PTSD Checklist-Military Version, and CESD-10 is a proactive approach to ensure that quick referrals and needed treatment can be provided in a timely manner. Finally, veterans clearly have a need for integrated care from multiple disciplines and specialties. The PCMH provides "one-stop shopping" for veterans and their families to receive the coordinated care they need. The short-form screens for PTSD and depression are easy to administer; are not a significant time burden for veterans, families, or physicians; and will provide physicians with important information with which to coordinate care if a multidisciplinary approach is required.

Care of veterans and their families' needs are illustrative of the potential benefits of a PCMH. Awareness of the unique challenges veterans and their families face and that their health outcomes are intertwined translates into better overall physical and mental health outcomes for all.

\section{References}

1. Kuzel A. Ten steps to a patient-centered medical home. Fam Pract Manage 2009;16:18-24.

2. Veterans Health Administration, Office of Public Health and Evironmental Hazards. Analysis of Veterans Administration health care utilization among US Global War on Terrorism (GWOT) veterans: Operation Enduring Freedom, Operation Iraqi Freedom. Washington DC: Veterans Health Administration; 2009.

3. Office of the Surgeon Multi-National Corps-Iraq, Office of The Surgeon General US Army Medical Command. Mental Health Advisory Team (MHAT) VI: Operation Iraqi Freedom 07-09. 2009. Available at: http:// www.armymedicine.army.mil/reports/mhat/mhat_vi/ MHAT_VI-OIF_Redacted.pdf. Accessed 16 September 2010.

4. Veterans Health Affairs. Analysis of VA healthcare utilization among US Southwest Asian war veterans: Operation Iraqi Freedom, Operation Enduring 
Freedom. Washington DC: Office of Public Health and Environment Hazards; 2006.

5. Gross R, Neria Y. Combat duty in Iraq and Afghanistan and mental health problems. N Engl J Med 2004;351:1798-800.

6. Engel AG, Aquilino CA. Combat duty in Iraq and Afghanistan and mental health problems. N Engl J Med 21;351:1798-800.

7. Office of the Command Surgeon US Forces Afghanistan, Office of The Surgeon General US Army Medical Command. Mental Health Advisory Team (MHAT) 6: Operation Enduring Freedom 2009Afghanistan: Office of the US Army Surgeon General; 2009.

8. Defense Manpower Data Center. Profile of currently deployed personnel, December 2009. Washington DC: Department of Defense; 2010.

9. Defense Manpower Data Center. Deployment by family status. Washington DC: Department of Defense; 2010.

10. Lapierre C, Schwegler A, LaBauve B. Posttraumatic stress and depression symptoms in soldiers returning from combat operations in Iraq and Afghanistan. J Trauma Stress 2007;20:933-43.

11. Burnam MA, Meredith LS, Tanielian T, Jaycox LH. Mental health care for Iraq and Afghanistan War veterans. Health Affairs (Millwood) 2009;28: 771-82.

12. Kavanagh J. Stress and performance: a review of the literature and its applicability to the military. Santa Monica, CA: RAND Corporation; 2005.

13. Seal KH, Bertenthal D, Miner CR, Sen A, Marmar C. Bringing the war back home: mental health disorders among 103,788 US veterans returning from Iraq and Afghanistan seen at Department of Veterans Affairs facilities. Arch Intern Med 2007; 167:476-82.

14. Substance Abuse and Mental Health Services Administration. Statistics on mental health. 2008. Available at http://www.samhsa.gov/SAMHSA_News/ VolumeXVI_1/article3.htm. Accessed 16 September 2010.

15. Wilk JE, Bliese PD, Kim PY, Thomas JL, McGurk D, Hoge CW. Relationship of combat experiences to alcohol misuse among US soldiers returning from the Iraq war. Drug Alcohol Depend 2008;108:115-21.

16. Smith B, Ryan MAK, Wingard DL, et al. Cigarette smoking and military deployment: a prospective evaluation. Am J Prev Med 2008;35:539-46.

17. Bullman TA, Kang. HK. The risk of suicide among wounded Vietnam veterans. Am J Public Health 1996;86:662-6.

18. Lambert MT, Fowler. RD. Suicide risk factors among veterans: risk management in the changing culture of the Department of Veterans Affairs. J Ment Health Adm 1997;24:350-8.

19. Hotopf M, Hull L, Fear N, et al. The health of UK military personnel who deployed to the 2003 Iraq war: a cohort study. Lancet 2006;367:1731-41.

20. Hoge C, Auchterlonie J, Milliken C. Mental health problems, use of mental health services, and attrition from military service after returning from deployment to Iraq or Afghanistan. JAMA 2006; 295:1023-32.

21. Vasterling J, Proctor S, Amoroso P, Kane R, Heeren T, White R. Neuropsychological outcomes of army personnel following deployment to the Iraq war. JAMA 2006;296:519-29.

22. Carroll EM, Rueger DB, Foy DW, Donahoe CP. Vietnam combat veterans with posttraumatic stress disorder: analysis of marital and cohabitating adjustment. J Abnorm Psychol 1985;94:329-37.

23. McElwain NL, Volling BL. Depressed mood and marital conflict: relations to maternal and paternal intrusiveness with one-year-old infants. J Appl Dev Psychol 1999;20:63-83.

24. McFarlane AC. Military deployment: the impact on children and family adjustment and the need for care. Curr Opin Psychiatry 2009;22:369-73.

25. Karney BR, Crown JS. Families under stress: an assessment of data, theory, and research on marriage and divorce in the military. Santa Monica, CA: RAND Corporation; 2007.

26. Hosek J, Kavanagh J, Miller L. How deployments affect service members. Santa Monica, CA: RAND Corporation; 2006.

27. Stellman JM, Stellman SD, Sommer JF. Social and behavioral consequences of the Vietnam experience among American Legionnaires. Environ Res 1988; 47:129-49.

28. Gamache G, Rosenheck R, Tessler R. Overrepresentation of women veterans among homeless women. Am J Public Health 2003;93:1132-6.

29. Gamache G, Rosenheck R, Tessler R. The proportion of veterans among homeless men: a decade later. Soc Psychiatry Psychiatr Epidemiol 2001;36:481-5.

30. Gamache G, Rosenheck R, Tessler R. Military discharge status of homeless veterans with mental illness. Mil Med 2000;165:803-8.

31. Levy BS, Sidel VW. Health effects of combat: a life-course perspective. Annu Rev Public Health 2009;30:123-36.

32. Pizarro J, Cohen Silver R, Prause J. Physical and mental health costs of traumatic war experiences among Civil War veterans. Arch Gen Psychiatry 2006;63:193-200.

33. Bramsen I, Deeg DJH, van der Ploeg E, Fransman S. Wartime stressors and mental health symptoms as predictors of late-life mortality in World War II survivors. J Affect Disord 2007;103:121-9.

34. Musheno M, Ross SM. Deployed: how reservists bear the burden of Iraq. Ann Arbor: The University of Michigan Press; 2008.

35. Friedemann-Sanchez G, Sayer NA, Pickett T. Provider perspectives on the rehabilitation of pa- 
tients with polytrauma. Arch Phys Med Rehabil 2008;89:171-8.

36. Faber AJ, Willerton E, Clymer SR, MacDermid SM, Weiss HM. Ambiguous absence, ambigous presence: a qualitative study of miltiary reserve families in wartime. J Fam Psychol 2008;22:222-30.

37. Manderscheid RW. Helping veterans return: community, family, and job. Arch Psychiatr Nurs 2007; 21:122-4.

38. Stenger RJ, DeVoe JE. Policy challenges in building the medical home: do we have a shared blueprint? J Am Board Fam Med 2010;23:384-92.

39. Regier DA, Narrow WE, Rae DS, Manderscheid RW, Locke BA, Goodwin FK. The de facto US mental and addictive disorders service system. Ep- idemiologic catchment area prospective 1-year prevalence rates of disorders and services. Arch Gen Psychiatry 1993;50:85-94.

40. Keane T, Fairbank J, Caddell J, Zimering R, Taylor $\mathrm{K}$, Mora C. Clinical evaluation of a measure to assess combat exposure. Psychol Assess 1989;1:53-5.

41. Andresen EM, Malmgren JA, Carter WB, Patrick DL. Screening for depression in well older adults: evaluation of a short form of the CES-D (Center for Epidemiologic Studies Depression Scale). Am J Prev Med 1994;10:77-84.

42. Kilbourne EM, Justice AC, Rollman BL, et al. Clinical importance of HIV and depressive symptoms among veterans with HIV infection. J Gen Intern Med 2002;17:512-20. 